\title{
$\mathrm{PH} 10 \mathbf{3}_{\text {deate }}$
}

a debate Dilemas del arte urbano como patrimonio

| coordinan Elena García Gayo y Laura Luque Rodrigo

\section{Arte y Patrimonio. Un discurso del tiempo-espacio desde lo urbano}

Adris Díaz Fernández | Grupo de investigación de Arte Urbano, Universidad de Monterrey, México

URL de la contribución <www.iaph.es/revistaph/index.php/revistaph/article/view/4898>

Cuando se menciona el espacio-tiempo en lo urbano, no nos referimos necesariamente a la teoría sobre la relatividad (1905) del físico matemático Albert Einstein, sino todo lo contrario, hacemos referencia a la dialéctica del tiempo-espacio desde una visión sociológica, partiendo del criterio que el arte responde a su realidad temporal y a un contexto. En el caso de "lo urbano" el tiempo también se explica como el contexto histórico, social y político en el que se desarrolla el arte de la ciudad ${ }^{1}$.

Por otro lado, el espacio se entiende como el llamado "espacio construido", concepto que abarca la comunidad, las calles, plazas y barrios; elementos que permiten la jerarquización del espacio, reconocer la vida social de los habitantes.

En base a lo explicado, resulta interesante plantear los siguientes interrogantes: ¿qué importancia se otorga al arte urbano dentro de la sociedad?, ¿cuál es el valor cultural de estos muros en el contexto ciudadano?

Para entender la ciudad es importante conocer las mutaciones que ocurren en ella, y es por esos cambios que las preguntas expuestas arriba revelan la necesidad de analizar el arte urbano no únicamente desde un punto de vista estético y de conservación, sino también desde la crítica sociocultural, entendiéndola como el estudio de la realidad cultural y social de la expresión artística. Atendiendo a este panorama, el arte urbano queda expuesto a la mirada invectiva o de defensa de quienes lo perciben.

No es un secreto que cualquier producción y/o interpretación de una creación artística se nutre de todo acontecimiento que la rodea. El arte urbano no es ajeno a este fenómeno y se sustenta de las apreciaciones, sensaciones e imaginarios existentes en la ciudad.

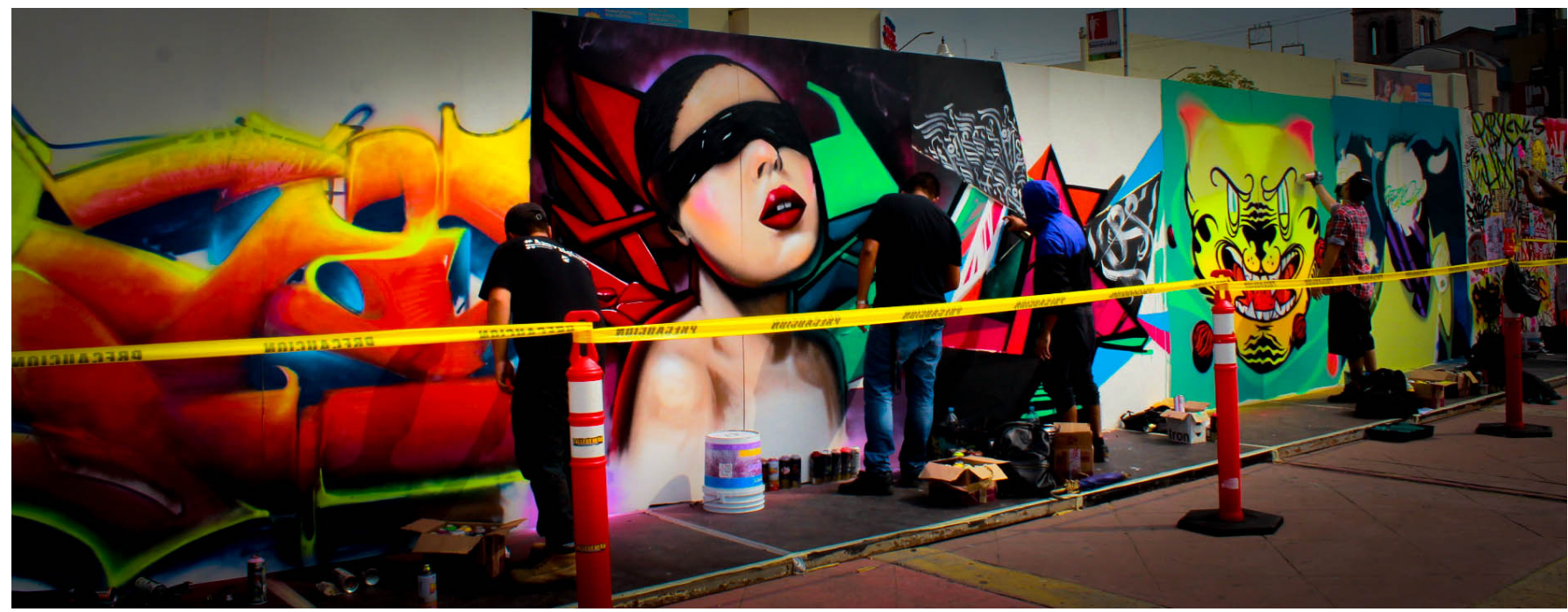

Callegenera, 2016 | foto Alfredo Vargas 


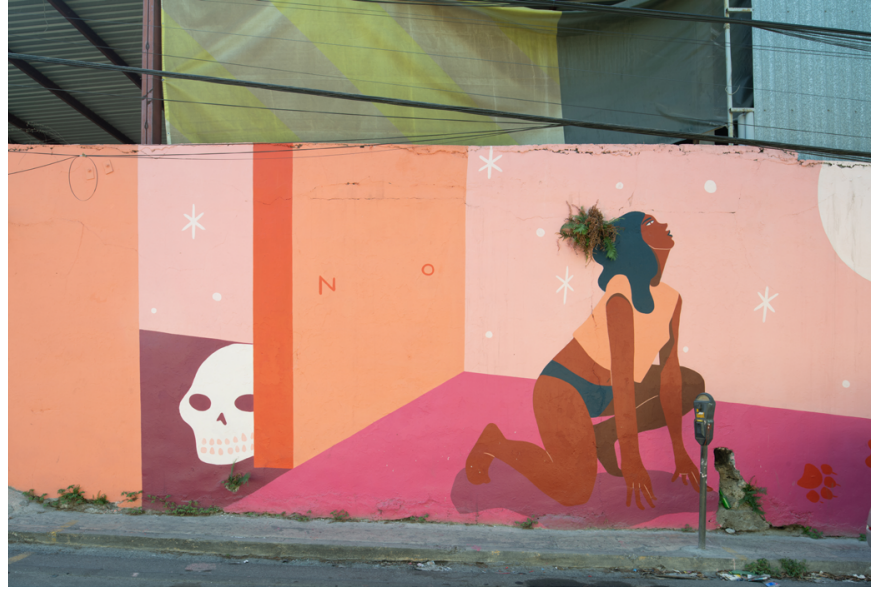

Festival de Expresiones Urbanas Callegenera, 2020. Mural de Vera Primavera sobre los feminicidios | foto Adris Díaz

Todo lo expuesto nos conduce a la cuestión: ¿el arte urbano es una parte intrínseca del patrimonio cultural de la ciudad? Como respuesta se puede afirmar que sí lo es, que estas creaciones muralistas logran, de alguna forma, conjugar todos los elementos antes mencionados.

El arte urbano, como tal, permite resignificar la ciudad, ofreciendo una personalidad propia a través del color, de sus figuras, sus dimensiones y sus mensajes. Cada obra o creación mural exteriorizada en la ciudad tiene algo que transmitir, obligando a los transeúntes y vecinos a convivir y sentir.

Las ciudades latinoamericanas toman el arte urbano como vía de canalización, protesta y explicación a situaciones sociales de resistencia; se emplea como un agente de bienestar en los espacios públicos que van encaminados a la revitalización y/o transformación; es un medio para rescatar tradiciones, glorificar los oficios , las personas del barrio y consolidar la comunidad.

El arte urbano, en ocasiones, busca trascender la frontera del embellecimiento para convertirse en la voz de aquellos que, siendo excluidos o vulnerables, no tienen la capacidad, el poder o las habilidades para ejercer sus derechos.

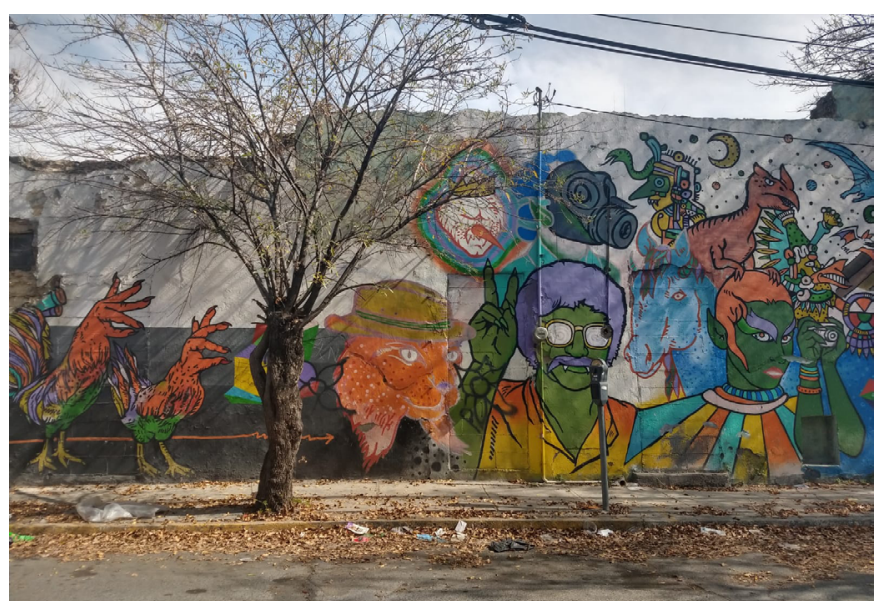

Festival de Expresiones Urbanas Callegenera, 2011 | foto Adris Díaz

Además, el arte urbano se presenta como un medio para transparentar las acciones del gobierno y para la reivindicación política, convirtiéndose en un objeto de crítica social y poder. También es una vía de preocupación sobre la situación medioambiental.

Hemos de explicar que no es de interés destacar nada más este aspecto, es decir, el dialogo entre la obra, el artista y el contexto; la idea gira en torno a su estudio y a la implicación e incidencia del arte urbano, buscando además de su conservación, conocer el imaginario de la ciudad. Insistimos en la necesidad de conocer el impacto del arte urbano en la sociedad, es decir, en el transeúnte, en el vecino, en el espectador.

Un ejemplo que ilustra los cambios que se están produciendo en la percepción del arte urbano es el relacionado con las intervenciones en el espacio público que no son patrocinadas exclusivamente por instituciones, asociaciones civiles, etc., sino que también reciben ayuda por parte de los gestores de la industria cultural, o de los partidos políticos, y que conviven con otra tendencia en la que el desarrollo de proyectos de intervención es generado por los propios artistas, de modo individual o colectivo, de forma que, de una manera libre y coordinada, logran plasmar algún tema en especial, acorde con lo ocurrido de interés en la ciudad. 


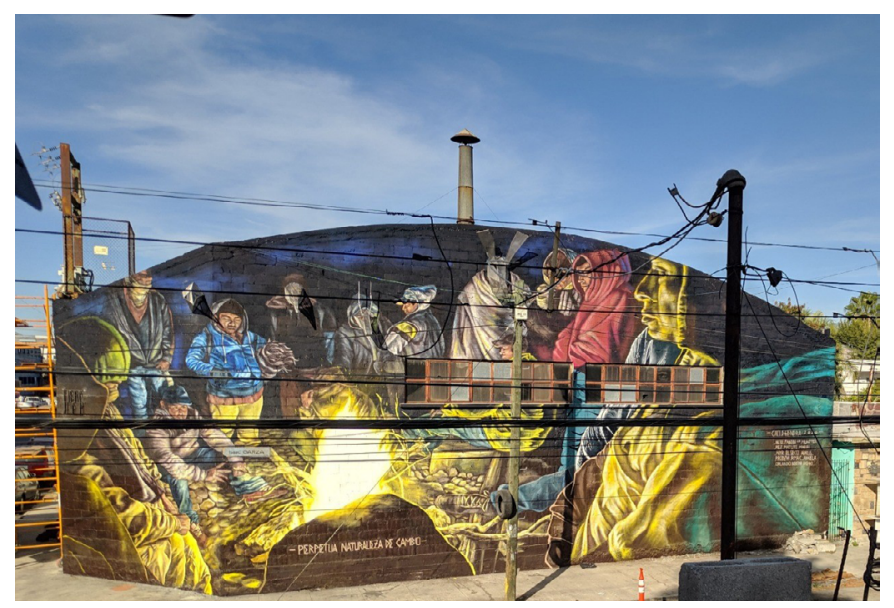

Festival de Expresiones Urbanas Callegenera, 2020. Mural Perpetua Naturaleza de cambio de Libre HEM sobre la migración | foto Edgar Favela

Señalamos también la evidencia de una producción tanto legal como ilegal y, de acuerdo al medio de gestión empleado para la intervención, así serán el tema a comunicar y los objetivos del mismo. Otro aspecto a destacar es el papel de la mujer en los procesos de intervención en la ciudad. Aun son pocas las que destacan, pero en los últimos años se ha producido una mayor proliferación de sus obras. Las mujeres, poco a poco, se han apropiado de los espacios que tradicionalmente han sido ocupados por los hombres, han hecho suyas las técnicas del arte urbano, en ocasiones para convertir los espacios de la ciudad en el soporte de las denuncias sociales.

La conjugación entre la creación mural, el espacio y el tiempo que transcurre en la ciudad aporta componentes para entender y reconceptualizar el fenómeno "arte urbano". Insistir en destacar este contexto es importante debido a que todas las realidades de intervención del arte urbano no tienen porqué ser iguales, puesto que, por un lado, es necesario despertar el interés por conocer la dinámica de actuación de los artistas o creadores urbanos en el tiempo-espacio de las ciudades latinoamericanas y, por otro, su impacto.

Se debe insistir en la necesidad de elaborar un pensamiento decolonial y poscolonial desde los ojos de quien estudia, con la finalidad de construir una mirada al arte urbano que abarque, además de sus características, sus particularidades como territorio, sin dejar de lado su cultura, desde un acontecer social, político e incluso económico. Es desde esta perspectiva que se alcanzará a entender la razón detrás de las intervenciones, sus temas, los espacios, la dinámica de intercambio y su repercusión en la sociedad.

El arte urbano no siempre es efímero, ni fugaz, ni contradictorio, pero sí es un arte asentido o descalificado por la sociedad; es un arte que, dado su naturaleza, se convierte en un ingrediente clave del patrimonio de la ciudad, independientemente de ser o no reconocido como patrimonio cultural. Por último, tomando en consideración todos los elementos anteriormente mencionados, se señala la urgencia de resaltar el arte urbano como patrimonio cultural, bajo la justificación de que es un medio eficaz para la construcción de una ciudadanía, como vía para reforzar sus postulados, especialmente en América Latina. Porque el arte urbano permite entender, de alguna manera, cómo se construye el imaginario de la ciudad, cómo se presentan las prácticas urbanas, aunado la revelación de la identidad y los modos de vida de las ciudades.

\section{NOTAS}

1. Esta evaluación del impacto del arte urbano y público desde el tiempo-espacio, desde lo sociocultural, es uno de los objetivos de la investigación La creación muralista del Festival de Expresiones Urbanas CALLEGENERA, estudio en el que están involucradas la Universidad de Monterrey y la Universidad Autónoma de Nuevo León, ambas de México.El equipo está conformado por Rodrigo Ledesma Gómez, Ana Cristina García- Luna, Yadira Nieves y Adris Díaz Fernández. 